\title{
FUTEBOL E LIMPEZA: A UTILIZAÇÃO DE METÁFORAS NA PUBLICIDADE BOM BRIL
}

\author{
Juliana Petermann \\ jupetermann@yahoo.com.br
}

\section{RESUMO}

O objetivo deste artigo é analisar a utilização de metáforas nos textos da campanha publicitária impressa dos produtos Bom Bril. Por meio da verificação da transferência de significados que ocorre, neste caso, da base (futebol) para o alvo (produtos Bom Bril), procurou-se detectar a qualificação dos termos do alvo a partir das propriedades dos termos da base. O processamento das metáforas pode também ser analisado a partir do conceito peirceano de semiose infinita, que descreve o encadeamento dos signos e as significações que se pode produzir através desse processo. Processo esse que nos textos publicitários, pode ser percebido como estratégia persuasiva.

\section{INTRODUÇÃO}

Partindo de uma perspectiva cognitivista, pode-se destacar, além dos usos literais da linguagem, também sua utilização figurada. É a partir desse aspecto que se consideram as metáforas e as analogias como representações desse uso da linguagem que permite uma ampliação dos significados daquilo que se está querendo dizer. Para Sternberg (2000), as metáforas têm a capacidade de aproximar dois substantivos, ressaltando as suas similaridades e, ao mesmo tempo, não descartando suas dissimilaridades. Ao evidenciar as similaridades entre dois elementos que estão sendo comparados, os significados de ambos expandem-se reciprocamente.

As metáforas e analogias são comumente utilizadas com diferentes campos do conhecimento e podem funcionar como método de enriquecer e ampliar os significados, levando conceitos de um campo do conhecimento para o outro e viceversa. É esse enriquecimento que se busca quando são utilizadas metáforas na publicidade, e principalmente nesse caso, aparecem como estratégias de persuasão.

Na publicidade Bom Bril, campanha que permaneceu por vinte e seis anos sendo veiculada com poucas alterações, as metáforas estão por toda parte, e são constituídas pelo texto não-verbal, que tem seu sentido explicitado pelo texto verbal. Fala-se de futebol, de política, de estereótipos culturais e de religião para divulgar produtos de limpeza. Neste artigo, são analisados alguns textos dessa campanha, criados para a veiculação na mídia impressa. Os anúncios analisados não foram, no 
entanto, veiculados: são peças criadas para a publicação em uma edição especial da revista Veja que sairia após a conquista do Pentacampeonato do Brasil na Copa do Mundo de 1998. Como o time brasileiro foi derrotado pelo time francês, a revista não foi publicada, assim como os anúncios, que posteriormente foram publicados no livro Soy Contra Capas de Revista (2000) da agência de propaganda W/Brasil, responsável pela campanha.

\section{DA BASE PARA O ALVO: A MIGRAÇÃO DE SIGNIFICADOS}

$\mathrm{Na}$ publicidade, as metáforas são comumente utilizadas como estratégias de persuasão, já que este tipo estilístico de analogia tem a propriedade de colocar em interação diferentes domínios do conhecimento (Sternberg, 2000), permitindo, por exemplo, que se fale de futebol para divulgar produtos de limpeza. Uma rede de significados que, em princípio, parecem mais atraentes ao público consumidor é utilizada para que se propaguem, através dela, sentidos não tão sedutores como os vinculados aos produtos de limpeza.

A persuasão em textos publicitários deve ir além do convencimento que, de acordo com Perelman \& Olbrechts-Tyteca (1996), não conduz a uma ação. Para estes autores quando existe uma preocupação com resultados, como há no caso da publicidade, persuadir é mais do que convencer, porque o convencimento está relacionado a tudo que é razão. Desse modo, mesmo convencido de algo, o consumidor pode não exercer a ação - a compra de determinado produto - por questões financeiras ou mesmo por inadequação do produto a suas necessidades, questões racionalizadas. Ao contrário, a persuasão está ligada a tudo que não é razão e por isso, neste jogo que é a publicidade, são utilizadas estratégias que buscam seduzir o consumidor por meio de questões emocionais, lúdicas e que produzem significações pela apresentação de valores amarrados a situações de prazer e satisfação pessoal. Na publicidade Bom Bril, as estratégias persuasivas são construídas com a utilização de metáforas que produzem a interação entre diferentes domínios do conhecimento. Esta interação proporciona, no caso dos textos estudados, a valorização dos produtos da Bom Bril a partir dos significados que circulam pelo domínio do futebol, tão estimado e reconhecido pelo povo brasileiro. 
Para Sternberg (2000), a concepção de interação dos domínios do conhecimento indica que as metáforas são muito mais do que uma comparação: a interação entre o domínio do conteúdo (alvo) e o domínio do veículo (base), provoca uma migração mútua de significados. Perelman \& Olbrechts-Tyteca (1996) confirmam essa suposição, utilizando a afirmação de Richards (apudPerelman \& Olbrechts-Tyteca, 1996) que enfatiza o caráter vivo e variado das relações entre os conceitos utilizados na metáfora e que caracteriza essa interação, em um transporte de significação de um conceito para o outro.

Dentre os mecanismos que envolvem transferências de significados entre base e alvo, Gentner \& Wolff (2000) afirmam que as metáforas podem transferir significados da base para o alvo. Este mecanismo é considerado, por esses autores, como um mecanismo de projeção: um processo de transferência de um domínio para outro. $O$ mecanismo de projeção transporta para o alvo os significados que estão presentes na base, assim, a mudança acontece no domínio do alvo. Nos textos publicitários de Bom Bril esse é o mecanismo de transferência que pode ser identificado. Os sentidos que circulam pelos termos da base, ou seja, o futebol, migram para os termos constituintes do alvo, os produtos Bom Bril. Nos anúncios analisados, a base pode ser facilmente identificada em função do texto não-verbal, constituído pelo Garoto Bom Bril, caracterizado como um jogador de futebol. Assim, os termos apresentados no texto verbal são lidos a partir do contexto do futebol e depois são aplicados ao produto.

Isso acontece em função de um processo que Gentner \& Wolff (2000) relacionam com o domínio do mapa metafórico. De acordo com esses autores, as metáforas são processadas por um alinhamento estrutural. Assim, os mapas metaforicamente estendidos são processados com uma velocidade proporcional ao domínio do mapa. Quando um alinhamento estrutural e um mapa metafórico são ativados, guiam a compreensão da metáfora, tornando sua leitura mais fluente. Nos anúncios da Bom Bril, o alinhamento estrutural e o mapa metafórico são iniciados a partir do texto nãoverbal que define os termos da base.

Antes da continuação do desenvolvimento dessa questão, é necessário que se esclareça algumas terminologias que diferem entre os principais autores utilizados como referência neste artigo. A diferença acontece entre as denominações de alvo e base, utilizadas por Gentner \& Wolff (2000) e doravante utilizadas neste texto; conteúdo e veículo, denominação proposta por Sternberg (2000); 
e tema e foro de Perelman \& Olbrechts-Tyteca (1996). Assim, pode-se equipar foro base - veículo da mesma forma que se pode fazê-lo com tema - alvo - conteúdo. Para Gentner \& Wolff (2000), o alvo é o tópico principal, sobre o que se fala na metáfora, e a base é o veículo utilizado para colocar em relação os diferentes domínios do conhecimento. Sternberg (2000) utiliza o termo conteúdo para descrever o sujeito da metáfora e veículo para o objeto. Já Perelman \& Olbrechts-Tyteca (1996) sustentam a idéia de que, em geral, as analogias e, conseqüentemente, as metáforas apresentam uma forma genérica do tipo: A esta para $B$ assim como $C$ esta para $D$. Dessa forma, o tema é o conjunto dos termos A e B, nos quais está localizada a conclusão, e o foro é representado pelos termos C e D, que servem de apoio para o raciocínio. Assim, se pode exemplificar um dos textos publicitários que ilustram este trabalho:

“Campeão na área. Na área de serviço, nada é mais prático: A sobra é sempre com ele. Prá-lixo, o saco de lixo da Bom Bril”

O texto vem acompanhado com a imagem do Garoto Bom Bril caracterizado como o jogador Aldair que, naquela ocasião, jogava pelo time brasileiro na pequena área do campo de futebol, atuando na defesa. Neste caso, a estrutura da metáfora pode ser entendida como: $O$ saco de lixo Bom Bril (A) é campeão na área de serviço (B) assim como o jogador (C) é campeão na área do campo de futebol (D). O produto aparece, então, como alvo (tema para Perelman \& Olbrechts-Tyteca,1996) e o futebol é utilizado como base (foro para Perelman \& Olbrechts-Tyteca, 1996). Gentner \& Wolff (2000) dizem ainda que, geralmente, a base é mais conhecida do que o alvo, e vem para esclarecê-lo. No exemplo dado, isso se confirma pela familiaridade que os brasileiros têm com o futebol. Assim, todos os significados que circulam ao redor deste termo são emprestados para o produto Prá-lixo, e, da mesma forma que as qualidades do jogador de futebol são transmitidas ao produto, o produto também qualifica o jogador. Isso porque mesmo que a maioria dos significados seja transferida da base para o alvo, quando dois diferentes domínios são colocados em paralelo em uma analogia, acontece ou uma valorização ou uma desvalorização de ambos. No caso destes textos publicitários, uma propícia valorização. 
Os elementos da metáfora ( $A$ e $C, B$ e $D$ ) não têm uma correspondência restrita de significados, mas a semelhança está na relação que existe entre eles ( $A$ e B, C e D) (Gentner \& Wolff, 2000). Essa idéia pode ser reforçada pelas palavras de M. Cazals (apud Perelman \& Olbrechts-Tyteca, 1996), ao dizer que uma analogia não é uma relação de semelhança, mas sim uma semelhança de relação. No exemplo acima, a palavra "sobra" explicita a relação entre os termos: a "sobra" da cozinha fica para o saco de lixo e a chamada "sobra" do futebol - quando outro jogador perde a bola na área do adversário - fica para o jogador. Nesse sentido, a equiparação não está entre os termos "saco de lixo Bom Bril" (A) e "jogador" (C), e "área de serviço" (B) e "área do campo de futebol" (D), o que se identifica é a semelhança de relação entre os termos constituintes da base e constituintes do alvo. A mensagem metafórica, aqui, é completada com a imagem do Garoto Bom Bril, caracterizado como o jogador Aldair, que veste a camiseta da seleção brasileira, ao lado da embalagem do saco de lixo Prálixo.

No entanto, Perelman \& Olbrechts-Tyteca (1996) indicam que a natureza dos termos nunca é indiferente, ou seja, mesmo não tendo uma correspondência restrita, os termos se aproximam em razão da própria analogia e acabam conduzindo a uma interação, que, de certa forma, valoriza ou desvaloriza os termos do alvo. No caso da publicidade, obviamente essa interação remeterá a uma valorização dos termos do alvo, aqueles que dizem respeito ao produto. Os termos referentes ao saco de lixo Bom Bril ( $A$ ) e ao jogador (C), e os referentes à "campeão na área de serviço" (B) e à "campeão na área do campo de futebol" (D) é que produzem a interação e a migração dos significados entre os diferentes domínios: o futebol e a limpeza. Aos termos A e $C$ estão amarradas às significações que dizem respeito a um bom desempenho com relação às "sobras" (e esse termo por si só já é metafórico e engloba significados já convencionalizados, que remetem ao domínio do futebol), tanto as que vão para o lixo quanto às do futebol. É a relação desses termos que sugere alguns significados como agilidade, praticidade e destreza, dos quais, supostamente, comungam o produto e 0 jogador. Aos termos B e D estão relacionados aspectos de localização e espaço. Aqui, o que coloca em relação os diferentes domínios é a palavra "área", que possibilita o jogo entre as diferentes significações, permitidas pelo termo com a colocação de um adjunto do nome. 
O que acontece com os termos "sobra" e "área" pode ser o que permite a analogia. Ambos os termos apresentam significados diferentes daqueles literais quando constituintes da base metafórica - o futebol. De acordo com Perelman \& OlbrechtsTyteca (1996), as metáforas podem adquirir significados convencionalizados, que serão acessados mais rapidamente pelo leitor. $E$ é isso que se pode perceber nesse exemplo: as palavras "sobra" e "área", quando inseridas no contexto do futebol, apresentam significados convencionalizados e que são rapidamente acessados por aqueles que possuem conhecimento desse domínio. O mesmo acontece com a palavra "meia" em outro texto da mesma campanha publicitária:

Campeão na meia.

O sabão Limpol perfumado é bom de lavar meia, calção, camiseta. E ainda é decisivo na hora de lavar louças. Grande revelação.

O texto vem acompanhado pela imagem do Garoto Bom Bril, caracterizado como o jogador brasileiro César Sampaio, que atuava no meio de campo, durante a Copa do Mundo de 1998. A expressão "campeão na meia" age como base acompanhada das palavras "decisivo" e "revelação", que também possuem significados convencionalizados no domínio futebol. Ao contrário do primeiro exemplo, no qual a tensão metafórica se dava ao se especificar o termo "área" com a utilização do adjunto "de serviço", restringindo o sentido do termo; neste caso, a tensão acontece com o uso da própria palavra em conjunto com outras do mesmo campo semântico, que acabam por definir seu sentido de peça do vestuário, como calção e camiseta, fazendo referência aos componentes do uniforme utilizado pelos jogadores. As palavras "decisivo" e "revelação" fazem migrar para o produto (alvo) as propriedades utilizadas para qualificar o jogador (base).

Perelman \& Olbrechts-Tyteca (1996) chamam esse significado convencionalizado de "metáforas adormecidas". Esses autores dizem que o adjetivo "adormecida" serve melhor do que outros, pois designa um estado que pode ser passageiro e que essas metáforas podem tornar-se novamente atuantes. E esse despertar de uma metáfora pode ser altamente persuasivo e propício para ser utilizado em textos publicitários que possuem tal intuito. Esses autores argumentam que a melhor forma de despertar uma 
metáfora é colocá-la novamente em uma analogia. Os exemplos citados acima são possibilidades de colocar uma metáfora novamente em ação. No último, a palavra "meia", que possui um significado convencionalizado no contexto do futebol, é animada por meio de confronto com seu aspecto mais corriqueiro, como peça do vestuário. Essa estratégia é destacada por Perelman \& Olbrechts-Tyteca (1996), quando dizem que "a repetição de uma expressão, uma vez no sentido metafórico, a outra no sentido próprio, também pode fazer uma metáfora reviver" (1996:461). Isso acontece também no primeiro exemplo, com a palavra "sobra", que é colocada em oposição a seu sentido trivial. No entanto, o fator que desencadeia o despertar da expressão metafórica, que perpassa pelo termo "área" é a colocação do adjunto "de serviço", que acaba invertendo o raciocínio do leitor pela mudança brusca no contexto e pela transferência de significados da base para o alvo.

Perelman \& Olbrechts-Tyteca (1996) consideram, a esse respeito, que o contexto de um meio cultural provoca, por si só, o entorpecimento de uma metáfora e que as expressões de determinado domínio, como as gírias e os termos profissionais, podem parecer metafóricos para aqueles que estão extrínsecos ao domínio, mas não para os que fazem parte dele. Dessa forma, os termos "meia", "área" e "sobra", não são metafóricos no contexto de uma partida de futebol, mas adquirem esse status quando confrontados com outros possíveis sentidos. Por isso, Gentner \& Wolff (2000) utilizam as palavras de Keysar e Bly (1995) para destacar que as metáforas não podem ser consideradas como transparentes semanticamente, já que as interpretações são enfaticamente direcionadas pela configuração do contexto, muito mais do que o idioma por ele mesmo. Assim, pode-se inferir que, para a compreensão de uma metáfora, a pessoa deve ter conhecimento do contexto a partir do qual foram extraídos os termos da base para que tais sentidos possam ser aplicados ao alvo.

$\mathrm{Na}$ publicidade Bom Bril, os significados que circulam entre os termos da base, o futebol, migram para os termos do alvo, promovendo a divulgação das qualidades do produto. O exemplo abaixo foi extraído de um anúncio que apresentava o Garoto Bom Bril caracterizado como o então técnico da seleção brasileira, Zagalo.

\section{Campeão na experiência.}

Aqui o que não falta é brio. 
Pinho Bril é penta com germes, bactérias e adversários em geral.

Este texto confirma o processo de migração dos significados da base - o futebol, personalizado na figura do técnico da seleção - para o alvo - o produto Pinho Bril. Todos os sentidos de tarimba, experiência e até de uma certa teimosia, que circulam pela figura do técnico Zagalo, são transferidos para o produto Pinho Bril, um dos produtos mais antigos com sob o jugo de tal marca. Na ocasião, o técnico Zagalo seria o único a participar das cinco vitórias do Brasil em Copas do Mundo, sendo então, o único penta campeão efetivamente. Esse termo é utilizado assim, como adjetivo para o produto, que consegue derrotar germes, bactérias e adversários em geral. Para relacionar de maneira mais evidente os termos da base e do alvo é utilizado, ainda, o trocadilho com a palavra "brio", característica do personagem em questão (Zagalo), e "bril", constituinte do nome do produto, concretizando assim, a transferência dos significados da base para o alvo.

\section{A METÁFORA E O PROCESSO DA SEMIOSE INFINITA}

O texto que segue foi retirado do anúncio que apresentava a imagem do Garoto Bom Bril caracterizado como o jogador Dunga, capitão da seleção brasileira na Copa do Mundo de 1998:

Campeão em rendimento.

Limpol Gel rende 3 vezes mais.

Concentrado, sem brincar em serviço, é o capitão da cozinha.

No domínio do futebol, "rendimento" remete a bom desempenho, que faz lembrar " $g o l$ ", que traz a idéia de "vitória", que produz sentidos de "alegria" e que, no final das contas, não tem ligação nenhuma com produtos de limpeza. No domínio dos produtos de limpeza, "rendimento" faz lembrar a relação de "custo x benefício", que remete a "economia", que conduz a significados de "praticidade", e que, por si só, não vende produtos de limpeza, pois estão amarrados à racionalidade e, como visto 
anteriormente, não conduzem a uma ação, porque são somente capazes de convencer e não de persuadir.

Essa conclusão mesmo parecendo apressada, e um tanto perigosa, pela afirmação de que significados racionalizados não vendem - afirmação apressada em um campo tão enigmático quanto o da publicidade e das suas formas de persuasão -, serve para ilustrar, de uma forma muito simplificada, o processo da semiose infinita de Pierce e sua função em processos metafóricos, como os destes textos publicitários, que proporcionam uma migração de significados da base para o alvo, a fim de produzir efeitos de persuasão.

Os sentidos metafóricos e os efeitos que se podem produzir através deles são melhor analisados quando se procura relacioná-los com o processo de interpretação, descrito por Eco (1991), a partir dos estudos peircianos. Para ele, o processo de interpretação é a tradução de um signo (expressão) em outra expressão, e utiliza-se das palavras de Pierce para sustentar essa idéia:

"Um signo, ou representamen, é alguma coisa que está para alguém no lugar de alguma coisa sob qualquer ponto de vista ou de volume. Volta-se para alguém, isto é, cria na mente dessa pessoa um signo equivalente, ou talvez um signo mais desenvolvido. Esse signo que ele cria o chamo interpretante do primeiro signo". (Pierce apud Eco, 1991:111)

Para Eco (1991), não há como interpretar uma expressão sem traduzi-la em outros signos. Assim, o interpretante não só dá conta de um aspecto do interpretado como também o desenvolve, fazendo conhecer novos sentidos sobre ele. O processo da semiose infinita é, por isso, inerente ao processo de interpretação, porque a tradução de um signo, por si só, pressupõe um encadeamento de outros signos. O que se pode inferir das explicações de Eco, a respeito da semiose infinita, é que nunca falamos de algo diretamente, mas sempre através de outros significados que o circulam.

O processo da semiose infinita implica uma cadeia ilimitada de signos, que são dispostos em uma espécie de rede, que Eco (2000) define como polidimensional, sem núcleos determinados e na qual os percursos entre os signos se alongam e se encurtam, aproximando uns dos outros sem caminhos definidos, com acesso direto e simultâneo, que define contatos sempre mutáveis. A falta de uma hierarquia e de um caminho definido entre os signos da cadeia da semiose infinita é o que garante que 
cada indivíduo possui uma interpretação diferente. Por isso que o exemplo dado no início deste tópico é uma ilustração muito simplificada do funcionamento do processo de semiose infinita, mesmo porque cada indivíduo, a cada diferente momento, desenvolverá uma cadeia alterada de signos.

Nas metáforas, a semiose infinita torna-se ainda mais complexa porque são colocados em paralelo dois diferentes domínios do conhecimento. Esses diferentes domínios se encontram na cadeia de signos, por meio dos termos que relacionam base e alvo. No caso do exemplo dado acima, a palavra "rendimento" que se refere à base - e isso fica claro com a imagem do Garoto Bom Bril caracterizado como o jogador Dunga - é aplicada ao alvo (produto), associando os domínios. A partir desse termo, pode-se supor, esquematicamente, uma cadeia que parte da interpretação desse signo, derivando os dois diferentes campos de significação. Um que diz respeito ao domínio do futebol e outro que é constituído pelos elementos do campo semântico da limpeza, mas que em algum ponto da rede de significação se encontram, transferindo os sentidos de um campo para o outro.

\section{CONSIDERAÇÕES FINAIS}

As metáforas, não só nos textos publicitários, mas em qualquer texto podem ser entendidas como efeitos de persuasão, produzidos através da transferência de significados de um domínio do conhecimento para outro. No caso específico da publicidade, essa estratégia pode ser utilizada para tornar mais sedutor um produto que inicialmente não possui essa característica. Mesmo que o consumidor necessite de determinado produto, como os de limpeza, as diversas marcas existentes no mercado podem determinar a compra em função do menor custo. No entanto, quando são agregados valores lúdicos e emocionais a esse produto, através da transferência de significados da base para o alvo, ele adquire uma atmosfera de entidade semiótica, que facilita o processo de compra pela circulação de outros significados.

Por esse motivo, a compreensão metafórica e o seu entendimento como estratégia de persuasão são fundamentais para que o consumidor exerça seu papel conscientemente, adquirindo aqueles produtos que lhe são realmente necessários. Como em qualquer outro texto, as metáforas podem se tornar uma armadilha para aqueles que não percebem o jogo de significância que se articula através delas. 
As metáforas podem ser analisadas também a partir de outro processo, que é o da semiose infinita, responsável pelo encadeamento de signos e constituída pelos processos de cognição (Nöth, 2003). Por ser constituída pelos processos de cognição, a semiose infinita determina uma interpretação individualizada, pois, exige uma cognição prévia de determinado campo do conhecimento (Nöth, 2003). Dessa maneira, mesmo que se busque, através do texto publicitário, estabelecer uma rede de significações, cada indivíduo a construirá de uma maneira diferente, em função dos seus conhecimentos já armazenados.

Os sentidos que dependem dos termos relacionados ao futebol constituem um mapa semântico que é domínio da maioria do povo brasileiro. Isso explica a sua intensa utilização na publicidade, pois faz circular valores que são capazes de apreender a atenção de um grande número de pessoas. Por esse motivo, as campanhas publicitárias brasileiras, muitas vezes, empregam conceitos relacionados ao futebol, à praia e ao carnaval, sempre adicionados pelo culto ao corpo, principalmente o feminino. Assim, os significados que circulam através desses campos, apresentados como base metafórica são transferidos sutilmente ao produto, seja uma determinada marca de cerveja, um banco - que em muitas peças publicitárias é relacionado à praia e a tranqüilidade de poder sentar-se à frente do mar, acessando sua conta bancária dali mesmo, com o notebook - ou produtos de limpeza, como os da Bom Bril.

\section{BIBLIOGRAFIA}

ECO, Umberto. Semiótica e Filosofia da Linguagem. São Paulo: Ática, 1991. . Tratado Geral de Semiótica. São Paulo: Perspectiva, 2000.

GENTER, Dedre; WOLLF, Philip. Metaphor and Knowledge change. In: Cognitive dynamics: conceptual changes in humans and machines. Mahwah, $\mathrm{NJ}$ : Lawrence Eribaum Associates. 1999

NÖTH, Winfried. Panorama da Semiótica: De Platão a Pierce. São Paulo: Annablume, 2003.

STERNBERG, Robert J. Psicologia Cognitiva. Porto Alegre: Artes Médicas Sul, 2000 
PERELMAN, Chaïm; OLBRECHTS-TYTECA, Lucie. Tratado da Argumentação: A nova Retórica. São Paulo: Martins Fontes, 1996

QUINN, Naomi; HOLLAND, Dorothy. Cultural Models in Language and Thought. Cambridge: Cambridge University Press, 1987.

W/BRASIL. Soy Contra Capas de Revista: 1001 Anúncios de Bom Bril. São Paulo: Negócio Editora, 2000. 